\title{
Comparison of Long Term Results Between Prolactin Secreting Adenomas and ACTH Secreting Adenomas
}

\author{
Kalmon D. Post and Jo-Ellen Habas
}

\begin{abstract}
A series of 100 prolactin secreting pituitary adenomas was reviewed and demonstrated an early cure rate of $85.2 \%$ with a cure rate of $89 \%$ if prolactin was less than $200 \mathrm{ng} / \mathrm{ml}$. For macroadenomas the cure rate was $50 \%$ giving an overall cure rate of $71 \%$ for the entire group. When long term ( $>5$ years) followup was obtained a $17 \%$ incidence of recurrence was noted for the microadenoma group with a $20 \%$ recurrence rate for the macroadenoma group. Secretory dynamic studies were done shortly after surgery and then after a delay. Many showed a return to normal prolactin secretory dynamics suggesting that the underlying hypothalamic regulation is normal in most patients. Abnormal secretory dynamics at 6 weeks post operative testing were not predictive of which patients would relapse as many patients who had abnormal dynamics early did not relapse even during prolonged followup. Conversely a normal response to provocative testing did not preclude late relapse. A similar series of 40 consecutive patients with Cushing's disease was reviewed. Tumor was found in all but three cases. $84 \%$ of patients were cured and thus far only one patient $(2.5 \%)$ has shown late recurrence with this occurring at $6^{2} / 3$ years following surgery with normal stimulatory dynamics present for five years. The implication is that hypothalamic regulation is normal in Cushing's disease as well. The differences in recurrence rates may be reflective of the aggressiveness with which one disease is treated, with the acceptance of a higher incidence of hypopituitarism as a consequence of more radical surgery for Cushing's disease.
\end{abstract}

RÉSUMÉ: Comparaison des résultats à long terme entre les adénomes secrétant de la prolactine et les adénomes sécrétant de l'ACTH Nous avons analysé une série de 100 adénomes hypophysaires à prolactine et nous avons constaté un taux de guérison précore global de $85,2 \%$, avec un taux de guérison de $89 \%$ lorsque la prolactine était inférieure à $200 \mathrm{ng} / \mathrm{ml}$. Pour les macro-adénomes, le taux de guérison était de $50 \%$ avec un taux de guérison global pour tout le groupe des prolactinomes de $71 \%$. Lorsqu'un suivi à long terme était obtenu ( 5 ans), une incidence de récidice de $17 \%$ était notée pour le groupe des micro-adénomes, avec un taux de récidive de $20 \%$ pour les macroadénomes. Des études dynamiques sécrétoires furent effectuées immédiatement après la chirurgie, et après un certain délai. Beaucoup de patients montraient un retour à la dynamique de sécrétion prolactinique, suggérant que la régulation hypothalamique de base reste normale chez la plupart des patients. Des altérations de la dynamique sécrétoire au contrôle postopératoire après 6 semaines ne permirent pas de prédire quels patients récidiveraient, car bien des patients avec dynamique altérée en postopératoire précoce ne présentèrent pas de rechute, même après un suivi prolongé. Inversement, une réponse normale à une épreuve de provacation ne permit pas de prédire une rechute tardive. Une série similaire de 40 patients consécutifs avec maladie de Cushing a été révisée. La tumeur fut trouvée dans tous les cas sauf trois. $84 \%$ des patients furent guéris et jusqu'à présent, un seul patient $(2,5 \%)$ a montré une récidive tardive, et ceci plus de 6 années après chirurgie et des épreuves de stimulation dynamique normales pendant cinq années. Ceci implique que la régulation hypothalamique est préservée également dans la maladie de Cushing. Les différences dans les taux de récidive pourraient refléter la plus grande agressivité avec laquelle est traitée la maladie de Cushing, laissant prévoir dans cette catégorie une plus forte incidence d'hypopituitarisme.

Can. J. Neurol. Sci. 1990; 17:74-77

We have reported the long term followup of patients with prolactinomas treated by transsphenoidal surgery. ${ }^{1}$ There was a $17 \%$ incidence of late relapse for microadenomas. This matched recurrence rates in multiple reports. ${ }^{2-6}$ Recently we reviewed our results with $\mathrm{ACTH}$ secreting adenomas and now compare those results with those from the prolactinoma series.

\begin{abstract}
Material
At Columbia-Presbyterian Medical Center 37 patients with Cushing's disease were seen between 1981-1987. Many of these patients were sent from practitioners outside our Medical Center; therefore, the preoperative evaluations were heteroge-
\end{abstract}

From the Department of Neurological Surgery (K.D.P.) and the Department of Medicine (J.E.H.), College of Physicians and Surgeons, Columbia University, New York

Reprint requests to: Kalmon D. Post, M.D., Professor and Vice Chairman, Department of Neurological Surgery, College of Physicians and Surgeons, Columbia University, New York, New York 10032 USA 
Table 1: Cushing's Disease

\begin{tabular}{cc}
\hline $\begin{array}{c}\text { Pre-op } \\
\text { ACTH pg/ml }\end{array}$ & $\begin{array}{c}\text { Number } \\
\text { of Patients }\end{array}$ \\
\hline $20-40$ & 6 \\
$40-60$ & 4 \\
$60-80$ & 9 \\
$80-100$ & 7 \\
$100-200$ & 6 \\
$200-400$ & $\frac{5}{37}$ \\
\hline
\end{tabular}

nous. All of the data, however, was reviewed by a member of the endocrine department and all surgery was performed by one surgeon. In those cases where doubt existed as to the diagnosis, further diagnostic testing was advised. In only one patient did the results of this testing change the diagnosis leading to cancellation of surgery.

ACTH levels varied from low normal to levels well above $200 \mathrm{pg} / \mathrm{ml}$ (Table 1). Microadenomas were present in 29, macroadenomas in 5, and tumor was not found in three. Three of the 37 were invasive tumors and it was not anticipated that the surgery would be curative.

At the time of transsphenoidal resection, a selective adenomectomy was carried out if definite tumor was seen. One patient had a total hypophysectomy performed initially as she was out of childbearing age group and definitive tumor was not seen.

\section{RESULTS}

Twenty-nine (78\%) of these patients were cured after the first operation. Followup of the patients not cured after the first operation resulted in three patients undergoing a second transsphenoidal procedure. All of these had a total hypophysectomy. Three other patients not cured by transsphenoidal surgery underwent bilateral adrenalectomy and radiation of the pituitary fossa (Table 2).

A total of thirty-five patients (95\%) appeared to have their disease under control from this initial therapy. 32 of 37 patients $(86 \%)$ appeared cured from transsphenoidal surgery alone.

Two patients underwent transsphenoidal surgery in which invasive tumors were debulked. One received radiation therapy and remained hypercortisolemic, and the other patient with a large invasive tumor is currently undergoing radiation therapy. One patient, apparently not cured, was followed closely for one year post surgery. She had a microadenoma seen on frozen section and consumed in that preparation. She improved clinically for a short time and then relapsed. Petrosal venous sampling showed low to low normal levels of ACTH with no gradient

Table 2: Cushing's Disease

\begin{tabular}{|c|c|c|c|c|}
\hline Patient & Microadenomas & Macradenomas & $\begin{array}{c}\text { Tumor Not } \\
\text { Found }\end{array}$ & Cured \\
\hline 37 & 29 & 5 & 3 & $32 *$ \\
\hline
\end{tabular}

between peripheral blood and petrosal sinus collections. Further evaluation is underway and thus far an ectopic source has not been demonstrated.

Only I patient who was in clinical and biochemical remission for over 6 years following selective adenomectomy has noted a recurrence. After endocrinological testing she underwent a second transsphenoidal procedure. She again appears to be "cured".

\section{Discussion}

Cushing disease is different from other hypersecretory pituitary tumors. Other common tumors have characteristic clinical presentations based upon direct actions of anterior pituitary hormones secreted in excess. They are usually diagnosed simply by measurements of excess hormones in appropriate clinical settings, e.g. amenorrhea, galactorrhea and elevated serum prolactin, acromegalic appearance and high growth hormone.

Pituitary tumors secreting elevated amounts of TSH or FSH/LH are very rare. Their diagnosis is also straight forward depending upon the presence of a high end organ hormone (T4 or E2/testosterone) and nonsuppressed levels of pituitary trophic hormones.

At the time of clinical presentation most growth hormone secreting tumors are visible radiographically. If prolactin is above a certain level (greater than $200 \mathrm{ng} / \mathrm{ml}$ ) there is usually change on radiographic studies as well. TSH and gonadotrophin secreting tumors are also demonstrable on CT or MRI scan at the time of diagnosis.

Tumors causing Cushings disease, however, are quite heterogenous and not always diagnosable by a simple measurement of pituitary ACTH or end organ (cortisol) hormones. They must be differentiated from other causes of hypercortisolism such as primary adrenal hypercortisolism, depression, and ectopic production of ACTH or CRF. Because of technical limitations of the assay, a low or suppressed ACTH level is often indistinguishable from a low normal one. Thus the diagnosis of primary or secondary hypercortisolism is occasionally difficult. A series of suppression and stimulation patterns characteristic of pituitary adenomas and not of ectopic trophic hormone production have been described, but none is absolute. In addition, adenoma demonstrable on CT or MR is the exception in Cushing's disease. Many tumors are found during surgery in patients with Cushing's disease which were not demonstrated preoperatively. On the other hand, there are many radiographic abnormalities which are seen on high resolution studies which do not correlate with the actual tumor found at surgery.

Petrosal venous sampling has been used recently in patients where the diagnosis of pituitary dependent Cushing's disease is unclear. ${ }^{7,8}$ In that setting a gradient between peripheral blood and petrosal sinus blood is necessary before carrying out transsphenoidal exploration. The diagnosis must be secure particularly if radiographic studies are normal as is usually the case.

The treatment of patients with other hypersecretory pituitary tumors is usually straight forward. Surgery while occasionally performed as an emergency to preserve vision and decompress the optic chiasm, is rarely urgent from an endocrinological point of view. Symptoms associated with increased prolactin or growth hormone are usually chronic and not life threatening. 
Those secondary to elevated TSH can be tempered by beta blockade until a definitive diagnosis is made. With Cushing's disease, however, the myriad of problems resulting from hypercortisolism (increased susceptibility to infections, accelerated atherogenesis, development of diabetes mellitus and hypertension, hypokalemia, osteoporosis, thrombogenesis) carry the risk of significant morbidity and even mortality.

Thus, the type of pituitary tumor causing Cushing's disease, which accounts for approximately 15\% of most series compared to prolactinomas at about $50 \%$, is clinically the most debilitating. It is also the most tedious and difficult to diagnosis definitively.

Once diagnosed, however, the management is less controversial than that of other pituitary tumors. Drug therapy, unlike that employed for the treatment of prolactinomas, has considerable ill effects. Transsphenoidal surgery can be curative in a high percentage of cases with Cushing's disease if there is minimal suprasellar extension. ${ }^{9-13}$ It is less effective with large invasive tumors and is useless if ectopic production has not been correctly diagnosed. In spite of the potential short comings, transsphenoidal adenomectomy is usually effective and is generally associated with low morbidity. It is now the unequivocal first choice in the management of Cushing's disease.

In 1984 we reported the long term followup of transsphenoidal selective adenomectomy for prolactinomas. ${ }^{1}$ The transsphenoidal selective resection of prolactinoma had high "cure" rates and low morbidity yet some reports of increasing frequency of late recurrent adenoma led to controversy. ${ }^{14}$ It was not clear at that time whether the mechanism for tumor development was primarily in the pituitary gland or whether there was an hypothalamic dysfunction as the pathogenesis. One report of a very high recurrence rate of hyperprolactinemia supported the view that patients may very well have had an underlying abnormality in the pituitary or the hypothalmus, therefore, raising serious question about the optimum treatment for prolactinoma. 14

In our experience, prolactin levels returned to normal after selective microadenoma resection in $88 \%$. There was a $17 \%$ incidence of late relapse. In patients with macroadenomas there was an early return to normal prolactin level in $37 \%$ with a $20 \%$ late relapse rate. We found that prolactin levels in those patients who relapsed was significantly higher both before and 6 weeks after surgery than in those patients who did not relapse. Similar observations were made by others.1,3,14 A post operative prolactin level of $15 \mathrm{ng} / \mathrm{ml}$ or higher was found to be predictive of patients who would suffer relapse.

It was not known whether the relapses were caused by late regrowth of tumor remnants left at the time of surgery or represented new tumor formation perhaps due to an underlying hypothalamic or pituitary abnormality. The return to normal prolactin secretory dynamics in many of the patients 6-8 weeks post operatively and the continuing trend to normalization found in the majority of patients tested over 4 years post operatively, suggested that underlying hypothalamic regulation was normal in most patients.' A similar trend towards normalization of prolactin secretory dynamics following surgical cure was found by others as well. 2,6

Abnormal secretory dynamics 6 weeks post operatively was not predictive, however, of which patients would relapse since many patients who had abnormal dynamics did not relapse even with prolonged followup. Conversely a normal response to provocative testing did not preclude relapse. Two surgically treated patients whose prolactin levels remained normal converted from normal to abnormal stimulatory responses to hypoglycemia. The continued conversion to normal stimulatory responses in most patients suggested that the early postoperative abnormal findings were probably secondary to the effects of the tumor on hypothalamic - pituitary function, and were not due to underlying dysregulation. Those patients with continued abnormal secretory dynamics may have had underlying hypothalamic dysregulation, slowly growing tumor remnants, or even generalized pituitary adnormalities.

In the Cushing's group, transient secondary adrenal insufficiency was seen in all cases when patients were "cured" after selective adenomectomy. This lasted 4-6 months and matched other reports. ${ }^{15}$ This is taken as evidence for a pituitary origin of the adenoma. Late recurrences were looked for in the Cushing's group with the anticipation that the recurrence rate might match that seen in the prolactinoma population. Thus far, only 1 patient who was in clinical and biochemical remission for over 6 years following selective adenomectomy has developed a recurrence. Within this period of time we would have anticipated a greater recurrence rate if the statistics from the prolactin group were at all predictive. This has not been the case suggesting that either the treatment is different or the nature of the initial disease is different.

Many patients presenting with hyperprolactinemia secondary to a secreting adenoma were concerned with infertility. The hyperprolactinemia had little negative effect other than causing infertility and possibly osteoporosis. It was our strong feeling that in those patients taken to surgery, the procedure itself could not be worse than the initial disease. Therefore a conservative operation was done. Every attempt was made to completely remove the tumor but not at the expense of normal pituitary function. In those patients not completely "cured" by transsphenoidal adenomectomy, bromocriptine offered excellent adjunctive treatment.

In Cushing's disease, however, the disease is acute with a high morbidity and mortality if left incompletely treated. While adrenalectomy will normalize hypercortisolism, the percent of patients developing Nelson's syndrome is significant. ${ }^{16} \mathrm{We}$ feel it much more advisable to focus treatment solely at the pituitary without adrenalectomy. Because of the natural history of the disease it has been our feeling that transsphenoidal resection ought to be aggressive. We are therefore willing to sacrifice more of the pituitary function than in patients with prolactinomas. This may account for some of the differences seen in the recurrence rate and long term cure rates for the prolactinoma patients versus the Cushing's disease patients. It may also be that longer followup is necessary in the Cushing's group to reflect a rising recurrence rate. Thus far, the aggressive surgical approach seems warranted and rewarded.

\section{REFERENCES}

1. Rodman EF, Molitch ME, Post KD, et al. Long term follow-up of transsphenoidal selective adenomectomy of prolactinoma. JAMA 1984; 252: 921-924.

2. Tucker HSG, Grubb SR, Wigand JP, et al. Galactorrhea-amenorrhea syndrome: followup of 45 patients after pituitary tumor removal. Ann Intern Med 1982; 94: 302-307. 
3. Giovanelli G, Gaini SR, Tomei G, et al. Follow-up review of microprolactinomas operated in 48 female patients. Excerpta Med Int Congr Ser 1982; 584: 189-196.

4. Camanni F, Ghigo E, Ciccarelli E, et al. Follow-up of 69 patients after pituitary tumor removal for hyperprolactinemia. Excerpta Med Int Congr Ser 1982; 584: 205-213.

5. Nencioni T, Miragoli A, Bertaglia MG, et al. Medical and surgical treatment of microprolactinomas: long term follow-up. Excerpta Med Int Congr Ser 1982; 584: 215-218.

6. Barharino A, DeMarinis L, Anile C, et al. Dopaminergic mechanisms regulating prolactin secretion in patients with prolactinsecreting pituitary adenomas: long term studies after selective Iranssphenoidal surgery. Metabolism 1982; 31: 1100-1104.

7. Oldfield EH, Chrousos GP, Schulte HM, et al. Preoperative lateralization of $\mathrm{ACTH}$-secreting pituitary microadenomas by bilateral and simultaneous inferior petrosal venous sinus sampling. N Engl J Med 1985; 312: 100-103.

8. Landolt AM, Valavanis A, Girard J, et al. Corticotrophin-releasing factor test used with bilateral, simultaneous inferior petrosal sinus blood-sampling for the diagnosis of pituitary-dependent Cushing's disease. Clin Endocrinol 1986; 25: 687-696.

9. Boggan JE, Tyrrell JB, Wilson CB. Transsphenoidal microsurgical manangement of Cushing's disease, report of 100 cases. J Neurosurg 1983; 59: 195-200.
10. Thomas JP, Richards SH. Long term results of radical hypophysectomy for Cushing's disease. Clin Endocrinol 1983; 19: 629-636.

11. Nakane T, Kuwayama A, Watanabe $M$, et al. Long term results of transsphenoidal adenomectomy in patients with Cushing's disease. Neurosurgery $1987 ; 21: 218-222$.

12. Hardy J. Presidential address: XVII Canadian Congress of Neurological Sciences. Cushing's disease: 50 years later. Can J Neurol Sci 1982; 375-380.

13. Styne DM, Grumbach MM, Kaplan SL, et al. Treatment of Cushing's disease in childhood and adolescence by transsphenoidal microadenomectomy. N Engl J Med 1984; 310: 889-893.

14. Serri $O$, Rasio $E$, Beauregard $H$, et al. Recurrence of hyperprolactinoma after selective transsphenoidal adenomectomy in women with prolactinoma. N Engl J Med 1983; 309: 280-283.

15. Fitzgerald PA, Aron DA, Findling JW, et al. Cushing's disease: transient secondary adrenal insufficiency after selective removal of pituitary microadenomas; evidence for a pituitary origin. J Clin Endocrinol Metab 1982; 54: 413-422.

16. Kasperlik-Zuluska AA, Nielubowicz J, Wislawski J, et al. Nelson's syndrome: incidence and prognosis. Clin Endocrinol 1983; 19: 693-698. 